\title{
THE RELATION OF VENEREAL DISEASE TO INDUSTRY
}

\author{
By WALTER M. BRUNET, M.D., Brooklyn, N.Y.
}

SYPHILIS and gonorrhœa have not been given due consideration as industrial handicaps in the United States until the past four years. It was as late as September, I9I9, that a medical leader said of syphilis, " That it could be regarded as a prolific source of industrial inefficiency has just dawned on the profession." Shortly after this, at a meeting of the American Association of Railroad Chief Surgeons, one of the members made the startling assertion that four recent wrecks had been traced to engineers suffering from paresis.

The publicity attained by the Government's work in combating venereal diseases during the War was responsible mainly for the continued interest in this question after the armistice. The industrial programme, prepared and distributed jointly by the U.S. Public Health Service and the American Social Hygiene Association, was sent to 57,000 industrial executives in the months prior to June 30th, I9I9, and from that date to April I5th, I922, has been sent to 61,396 more. The programme consists of a warning placard, brief pamphlets on the symptoms and treatment of the diseases for distribution to the workers, and a letter to the plant executive urging cooperation. A total of $1,464,705$ copies of the placards and pamphlets have been sold, and we may assume that the distribution has been made with some degree of care, since business managers, like other individuals, are more considerate of literature when it must be paid for.

Many requests have been received for information on the cost of venereal disease to industry, but direct data and statistics from industrial records are scant. We have been compelled to make most of our deductions from Army and Navy figures, though recognising that many factors exist therein which are not applicable to civilian conditions.

The draft army of the United States was composed of 3I6 


\section{RELATION OF DISEASE TO INDUSTRY}

men taken from all strata - the same men who make up a large percentage of the industrial army. The following facts and figures on prevalence and cost are, therefore, indications worth noting :-

"Of the 967,486 men in the group known as the ' second million,' there were 54,843 , or 5.6 per cent., infected with a venereal disease." The annual report of the Surgeon-General of the Army for I9I9, in comparing these figures with those for the first 500,000 and first million, says: "It is probable that the figures for the second million of 5.6 per cent. showed more clearly the correct percentage of the drafted men from civil life who were infected." During the year I9I7, gonorrhœa was the commonest cause of admission to sick report among soldiers in the United States, and in I9I8 was second only to influenza. In I9I8, syphilis, gonorrhœa, and chancroid together were second only to influenza in number of admissions, exceeding by $87,87 \mathrm{I}$ admissions bronchitis, the next most frequent cause. Hence it is evident that, with the exception of the unusual epidemic of influenza which prevailed in I9I8, venereal infection was the greatest cause of disability in the U.S. Army during the world war. The two years I9I7 and I9I8 witnessed the entrance of approximately 3,500,000 men into the U.S. Army by induction or voluntary enlistment. In these two years the total time loss to the entire Army from venereal disease was 4,825,66I days-2,4I2,830 days per year. A low estimate of the number of men employed in the United States in manufacturing industries alone, to-day, places it at 10,000,000. Based on the above Army figures, the yearly time loss through venereal disease in this one group of industries is $6,893,800$ days. If we consider the estimate of 40,000,000 men in various kinds of labour in the United States, these figures would be quadrupled. As for the actual financial loss, it cannot be approximated, since this would necessitate figuring in the time lost through such complications as gonorrhœal rheumatism and the various syphilitic conditions, decrease in working activity, and increased liability to accident.

These Army statistics cannot be applied literally to industry, as treatment was obligatory in the service, and men were withdrawn from the ranks for longer periods than they would be absent from business. The figures indicate, however, a fair estimate of time necessary for 


\section{BRITISH JOURNAL OF VENEREAL DISEASES}

thorough treatment. Then, too, it must be understood that while a worker would not always be actually out of employment ten days, as in the Army, he would nevertheless be ailing and non-effective in his work oftentimes to a greater extent than the Army's ten-day average represents.

Among the factors making for this are $(a)$ time required to attend a clinic; $(b)$ lack of ability to concentrate on work (particularly patients with epididymitis or tight strictures, and those in all stages of syphilis) ; (c) worry over danger of infecting co-workers or marital partners ; (d) necessity for frequent micturition. An additional item of expense to employers is the extra compensation paid to injured employees by insurance carriers for accidents where syphilis and gonorrhœa are contributing agents towards delaying recovery.

The first question asked by an executive is : " How best can industry co-operate in combating these diseases?" This may be answered as follows :-

First, by seeing that the community has treatment facilities in the form of a venereal disease clinic as part of (I) a general dispensary connected with a hospital, (2) a health centre doing treatment work, or (3) an isolated clinic under official (health department) auspices. In this connection one plant doctor claims that far better results can be secured by subsidising local public clinics for treatment purposes than by spending the same amount for a plant venereal disease clinic.

Secondly, by doing educational work within the plant, placarding the plant extensively and distributing educational material to the employees.

Thirdly, by providing better environmental conditions and more wholesome recreational facilities.

The foundation of the whole campaign is the public health equipment of the community. It is essential that this be in a condition to function, for education and recreation cannot do a complete job without it. In fact, some educational campaigns have failed because local clinics, when confronted with a large number of new cases, have curled up and died.

A second question usually asked by the executive is : "Will the clinic be extensively patronised?" Health officials answer this in the affirmative on the following grounds. Oftentimes the men have been cheated by 


\section{RELATION OF DISEASE TO INDUSTRY}

quacks; others have gone to ethical doctors who have proved incompetent in the diagnosis and treatment of venereal cases. Many, to their sorrow, have experimented with " three-day" gonorrhœa cures and other over-the-counter nostrums. When they learn, therefore, that their own plant is co-operating in a national campaign to provide adequate medical facilities under skilled supervision, they are quick to take advantage of these facilities. Any idea that the owners or executives have ulterior motives in aiding this movement has been thoroughly removed by the knowledge that the Government has asked their aid and that the American plan for controlling and preventing venereal diseases has been endorsed by the American Federation of Labour.

A few actual examples of work already accomplished will emphasise the need for and value of these measures. A northern New York firm having 3,000 male employees followed the Government's suggestions and adopted educational and clinical measures. Thirty cases applied for treatment within the first few weeks. One man had spent $\$ 800$ for quack treatment, which, as is usually the case, had failed to provide the promised cure. By placing the case in the hands of a competent doctor and expending $\$ 50$, the company brought about his cure.

An influential manufacturing concern in West Virginia followed the advice of a health expert and aided in installing a clinic for the free treatment of venereal disease at a cost of between $\$ 5,000$ and $\$ 6,000$ for the first year. The plant had a pay-roll during this period of $\$ 125,000$. The president of the firm has informed the United States Public Health Service that, as a result of the clinic treatment, labour efficiency was improved $33 \frac{1}{3}$ per cent., which gave him a return of $\$ 40,000$ from the investment.

A corporation, among its other activities, built a city in a wilderness for the housing of thousands of men and women employees. When efficiency dropped below expectations, the officials sent experts to conduct a survey and find the cause. This investigation showed :-

(I) That one employee in every ten had a venereal disease.

(2) That 68 per cent. of non-effectives were on the noneffective list because of venereal diseases.

v.D. 


\section{BRITISH JOURNAL OF VENEREAL DISEASES}

(3) That every person who had a venereal disease lost three times as many hours from work as every person not affected.

(4) That it cost every person so afflicted $\$ 75$ per year for treatment : a total of $\$ 50,000$ for treatment, with a loss of time greatly exceeding this amount.

This survey convinced the officials that it would repay them to take steps to remedy the situation, and they asked the United States Public Health Service for help. An immediate response was forthcoming and co-operation given toward the establishment of clinics where the employees could be treated. In a comparatively short time the cost of operating the clinics was entirely offset by increased production.

It is not an uncommon thing nowadays for groups of industries to combine in making an adequate appropriation for the local health department to work with. They are realising that disease cannot be controlled from within the plant, but that certain helpful measures can be carried on therein. These general truths apply specifically to the fight against syphilis and gonorrhoa, a public health campaign presenting the opportunity for a combination of true altruism and good business judgment. 